\title{
The immunogenicity of recombinant Mycobacterium smegmatis bearing BCG genes
}

\author{
Valeria Falcone, ${ }^{1} \dagger$ Effiong Bassey, ${ }^{1} \ddagger$ William Jacobs, $\mathrm{Jr}^{2}$ \\ and Frank Collins's
}

Author for correspondence: Frank M. Collins. Tel: +1 301496 5045. Fax: +1 3014022776.

1 Trudeau Institute, Saranac Lake, New York 12983, USA

2 Howard Hughes Medical Institute, Bronx, New York, USA

\begin{abstract}
Specific pathogen-free C57BL6 mice infected with recombinant Mycobacterium smegmatis (rM. smegmatis) bearing BCG genes showed increased splenic survival compared to those receiving the vector control (plasmid DNA only). The mouse-passaged rM. smegmatis (J3R) survived in peritoneal macrophages better than the vector control, regardless of whether the macrophages were infected in vivo or in vitro. When rM. smegmatis J3R was cultured in synthetic Proskauer-Beck-Tween medium, protein bands characteristic of BCG culture filtrates and not present in the vector control preparation were observed. Mice immunized with two doses of heat-killed J3R suspended in Freund's adjuvant were able to limit the growth of virulent Mycobacterium tuberculosis within the lung and spleen compared to that observed in control mice receiving adjuvanted vector control or Freund's adjuvant alone.
\end{abstract}

Keywords: Mycobacterium smegmatis, BCG genes, macrophages

\section{INTRODUCTION}

Bacille Calmette-Guérin (BCG) has been used for more than 70 years for the prevention of pulmonary tuberculosis, especially in children living in Third World countries. Despite the widespread use of the BCG vaccine, as much as one third of the world's population is infected with tubercle bacilli, with 8 million new cases and nearly 3 million deaths being reported each year (Sudre et al., 1992). As a result, tuberculosis is still the most important life-threatening bacterial disease in the world today and has recently been declared to be a global health emergency by the World Health Organization (WHO, 1993). Neonatal immunization with live BCG vaccine constitutes the major component of tuberculosis control programmes in many parts of the world, despite questions raised by several recent field trials regarding its overall protective value (Fine, 1989). As a result of uncertainties regarding the protective ability of currently available BCG vaccines, a number of proposals have been made to increase the

\footnotetext{
† Present address: Institute of Medicine, University of Pavia, Varese, Italy.

‡ Present address: Department of Pathological Science, University of Wisconsin, Madison, WI 53706, USA.

$\int$ Present address: Mycobacteria Laboratory, Center for Biologics Evaluation and Research, FDA, Bethesda, MD 20892, USA.

Abbreviation: rM. smegmatis, recombinant Mycobacterium smegmatis.
}

immunogenicity of existing BCG vaccines by cloning more protective genes and transferring them into suitable carriers (Bloom, 1989; Curtiss et al., 1989). The recent development of the integrating shuttle cosmid (Snapper $e t$ al., 1988) makes it possible to transfer genetic material from one mycobacterial species to another and could lead to the development of new, improved vaccines for use against this important human disease (Collins, 1991).

The present study examines the ability of recombinant Mycobacterium smegmatis (rM. smegmatis) selected in vivo and bearing BCG genes to produce protein antigens capable of enhancing resistance to the growth of virulent tubercle bacilli within the lungs of aerogenically challenged mice.

\section{METHODS}

Animals. Specific pathogen-free C57BL/6 mice ( $6-8$ weeks old) were obtained from the Trudeau Animal Breeding Facility, Saranac Lake, New York. They were maintained under barrier conditions and fed sterilized commercial mouse chow and acidified water ad libitum (Collins, 1972).

Organisms. Mycobacterium bovis BCG Pasteur (TMC 1011) and Mycobacterium tuberculosis H37Rv (TMC 102) were obtained from the Trudeau Mycobacterial Culture Collection, Saranac Lake, New York. They were grown in Proskauer-Beck-Tween (PBT) liquid medium enriched with $10 \%$ oleic acid/albumin/ dextrose/catalase additive, harvested after incubation at $37^{\circ} \mathrm{C}$ for $10 \mathrm{~d}$ (mid-exponential growth phase) and dispensed into 
$1 \mathrm{ml}$ ampoules which were kept frozen at $-70^{\circ} \mathrm{C}$ until required (Kim \& Kubica, 1972). M. smegmatis strain $\mathrm{mc}^{2} 155$ was derived from M. smegmatis ATCC 607 (Snapper et al., 1990) and was cultured in PBT medium at $37^{\circ} \mathrm{C}$ for $3 \mathrm{~d}$ before being stored at $-70^{\circ} \mathrm{C}$. The viability of the recombinants was checked by thawing randomly selected ampoules, sonicating the organisms briefly to disperse any clumps and plating tenfold saline dilutions on Middlebrook $7 \mathrm{H} 11$ agar (Difco) enriched with $10 \mu \mathrm{g}$ kanamycin $\mathrm{ml}^{-1}$ (Snapper et al., 1988). Plates were incubated at $37^{\circ} \mathrm{C}$ in sealed plastic bags and the colonies counted using a plate microscope.

Construction of $M$. smegmatis/BCG recombinant pools. A genomic library from $M$. bovis BCG Pasteur, which had been grown as a surface pellicle on Proskauer and Beck medium for $14 \mathrm{~d}$ at $37^{\circ} \mathrm{C}$, was prepared by mechanical disruption and phenol/chloroform extraction (Grosskinsky et al., 1989). The DNA was digested into 30-50 kb fragments with Sau3A before being ligated to the integrating shuttle cosmid vector $\mathrm{PYUB178}$ (Jacobs et al., 1991). The pYUB178:: BCG DNA or pYUB178 DNA was electroporated into $M$. smegmatis $\mathrm{mc}^{2} 155$ which had been grown in PBT medium for $3 \mathrm{~d}$ at $37^{\circ} \mathrm{C}$ (Snapper et al., 1988). Separate pools of approximately 250 transformants were selected from kanamycin agar (theoretically sufficient to represent the entire BCG genome) and picked into $50 \mathrm{ml}$ Middle-

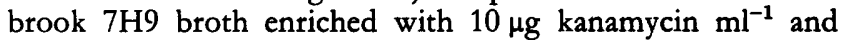
incubated at $37^{\circ} \mathrm{C}$ for $3 \mathrm{~d}$. The vector control (pYUB178) was prepared as a pool of 15 transformants. The recombinant pools were dispensed in $5 \mathrm{ml}$ aliquots and stored at $-70^{\circ} \mathrm{C}$ until needed.

Infection and enumeration of recombinant bacteria in vivo. A frozen ampoule was thawed, sonicated briefly to break up any clumps and suitable saline dilutions were injected intravenously into $\mathrm{C} 57 \mathrm{BL} / 6$ mice. Each mouse received approximately $10^{6}$ c.f.u. of each recombinant suspended in $0.2 \mathrm{ml}$ saline. At intervals up to $14 \mathrm{~d}$, groups of five randomly selected mice were killed by cervical dislocation, and selected organs were removed aseptically and homogenized separately in cold sterile saline before being plated on Middlebrook 7H11 agar enriched with $10 \mu \mathrm{g}$ kanamycin $\mathrm{ml}^{-1}$. Colonies were counted after $3 \mathrm{~d}$ incubation at $37^{\circ} \mathrm{C}$, representative rough, opaque colonies were checked for purity and a $3 \mathrm{~d}$ broth culture was stored at $-70^{\circ} \mathrm{C}$ until required.

Challenge protocol. Groups of vaccinated and control mice were infected aerogenically with approximately $10^{3}$ c.f.u. $M$. tuberculosis H37Rv using a Middlebrook chamber (Collins, 1985). The size of the challenge was checked by sacrificing five control mice $1 \mathrm{~h}$ later and plating the lung homogenate on Middlebrook $7 \mathrm{H} 11$ agar. The plates were incubated at $37^{\circ} \mathrm{C}$ in sealed plastic bags for up to $21 \mathrm{~d}$ and the average number of c.f.u. per organ was calculated. The standard counting error for five replicate determinations was usually less than $10 \%$ of the mean.

Infection of mouse macrophages in vivo. Peritoneal exudate macrophages were infected with mouse-passaged $\mathrm{r} M$. smegmatis J3R or vector control suspensions. The exudate was induced by the intraperitoneal injection of $2 \mathrm{ml} 10 \%(\mathrm{w} / \mathrm{v})$ casein in saline and the peritoneal cavity was washed out $3 \mathrm{~d}$ later using $5 \mathrm{ml}$ RPMI 1640 medium enriched with $10 \%(v / v)$ heat-inactivated foetal calf serum (Gibco) plus $5 \mathrm{U}$ heparin $\mathrm{ml}^{-1}$ (Stokes \& Collins, 1988). The peritoneal exudate cell suspension was washed twice with RPMI plus $1 \%$ FCS and the number of viable cells was determined by trypan blue exclusion. The cells were suspended at a concentration of $2 \times 10^{6}$ cells per $\mathrm{ml}$ of RPMI 1640 medium containing 10\% FCS, $1 \mathrm{mM}$ sodium pyruvate, $2 \mathrm{mM}$ L-glutamine and $10 \mathrm{mM}$ HEPES (complete medium), dispensed into 24-well plates (Costar) and incubated at $37^{\circ} \mathrm{C}$ in $5 \% \mathrm{CO}_{2}$-enriched humidified air for $24 \mathrm{~h}$. Nonadherent cells were removed by gentle washing and at least $95 \%$ of the adherent cells were determined to be macrophages based on non-specific esterase staining (Hubbard \& Collins, 1991).

Macrophage monolayers were infected with $10^{6}$ c.f.u. mycobacteria suspended in $1 \mathrm{ml}$ complete medium and incubated in $\mathrm{CO}_{2}$-enriched air for $4 \mathrm{~h}$ at $37^{\circ} \mathrm{C}$. The monolayers were washed gently with RPMI plus $10 \%$ FCS before adding $1 \mathrm{ml}$ complete medium containing $5 \mu \mathrm{g}$ gentamicin $\mathrm{ml}^{-1}$ (the MIC for $M$. smegmatis) and reincubating at $37^{\circ} \mathrm{C}$ for up to $48 \mathrm{~h}$. At approximately $6 \mathrm{~h}$ intervals, coverslips were removed from three of the wells, washed twice with warm PBS $(0 \cdot 145 \mathrm{M} \mathrm{NaCl}$, $0 \cdot 15 \mathrm{M}$ sodium phosphate, $\mathrm{pH} 7 \cdot 4$ ), fixed and then stained by the Ziehl-Neelsen method to determine the percentage of infected macrophages and their multiplicity of infection. Other coverslips were treated with naphthol blue black (Sigma) at a concentration of $0.5 \mathrm{mg}(\mathrm{ml} 0.1 \mathrm{M} \text { citric acid })^{-1}$ and $1 \%$ Triton $\mathrm{X}-100$ (Stokes et al., 1986). This solution lysed the adherent cells releasing any intracellular mycobacteria and the phagocyte nuclei. The bacteria were counted by immediately diluting $0.1 \mathrm{ml}$ of the lysate in $0.9 \mathrm{ml} 0.2 \mathrm{M}$ phosphate buffer ( $\mathrm{pH} 7.4$ ), which was briefly sonicated to disperse any clumped bacteria, and plating on agar enriched with $10 \mu \mathrm{g}$ kanamycin $\mathrm{ml}^{-1}$. Colonies were counted after $3 \mathrm{~d}$ incubation at $37^{\circ} \mathrm{C}$. The number of macrophages per well was determined by counting the stained nuclei using a haemocytometer. Viable mycobacteria were expressed per $10^{5}$ macrophages present on the monolayer at the time of harvest (Stokes et al., 1986).

Infection of mouse macrophages in vivo. Normal mice were injected intraperitoneally with casein $3 \mathrm{~d}$ prior to inoculation with $10^{6}$ c.f.u. M. smegmatis suspended in $0.5 \mathrm{ml} \mathrm{0.05 \%} \mathrm{Tween/}$ saline. The mice were sacrificed $10 \mathrm{~min}$ later and their peritoneal cavities washed out with $5 \mathrm{ml}$ RPMI 1640 medium containing $10 \%$ FCS plus heparin. The cell suspension was washed, its viability was checked by trypan blue exclusion and diluted to $2 \times 10^{6}$ cells (ml complete medium $)^{-1}$. The infected cells were cultured in 24 -well plates in $5 \% \mathrm{CO}_{2}$-enriched air for $2 \mathrm{~h}$ when the monolayers were washed gently to remove non-attached cells before being replaced with complete medium containing $5 \mu \mathrm{g}$ gentamicin $\mathrm{ml}^{-1}$. The average number of viable mycobacteria was calculated per $10^{5}$ macrophages from three wells per time point.

M. smegmatis culture filtrate antigens. The mycobacteria were grown in Proskauer-Beck-Tween medium without added albumin (Collins et al., 1988) and harvested during the midexponential growth phase ( $3 \mathrm{~d}$ for $M$. smegmatis and 8-10 d for $M$. bovis BCG). Cells were removed by centrifugation at $10000 \mathrm{~g}$ for $30 \mathrm{~min}$ at $4{ }^{\circ} \mathrm{C}$ and the supernatant fluid was sterilized by filtration through a $0.22 \mathrm{~mm}$ pore-size membrane (Millipore). Proteins were precipitated by $80 \%$ ammonium sulfate saturation at $4^{\circ} \mathrm{C}$ overnight. The precipitate was dissolved in $0.5 \mathrm{M}$ PBS ( $\mathrm{pH} 7 \cdot 4$ ) and dialysed in the cold until free of ammonium ions. The protein content was determined using the bicinchonic acid assay (Pierce) against a bovine serum albumin standard (Hubbard et al., 1992). Culture filtrate proteins were separated by SDS-PAGE run under reducing conditions in an $11 \%(\mathrm{w} / \mathrm{v})$ acrylamide gel and stained with Coomassie blue (Collins et al., 1988).

Statistical analysis. The viability data were analysed by Student's $t$-test or an analysis of variance for differences between two or several independent means using a Statview $512+$ program (Brainpower, Calabases) run on a Macintosh SE computer. 


\section{RESULTS}

\section{Mouse passage of $M$. smegmatis (pYUB178:: BCG)} recombinants

C57BL/6 mice were infected intravenously with the $M$. smegmatis recombinant pool. Viable counts were carried out on spleen (Fig. 1) and lung homogenates (data not shown) at intervals up to $14 \mathrm{~d}$. The number of viable recombinants present in the spleen declined steadily with time and did not resemble the growth of BCG in normal mice (Collins, 1984). Colonies were selected from the day 14 splenic homogenates plated on kanamycin agar, checked for purity and grown in $7 \mathrm{H} 9$ broth for $3 \mathrm{~d}$, then stored at $-70^{\circ} \mathrm{C}$ until required.

\section{Growth of $\mathrm{rM}$. smegmatis J3R in mouse macrophages}

Peritoneal exudates were induced in C57BL/6 mice and the macrophage monolayers were infected $24 \mathrm{~h}$ later with approximately $10^{6}$ c.f.u. mouse-passaged $\mathrm{r} M$. smegmatis J3R or the vector control. The number of viable organisms was then determined at intervals up to $48 \mathrm{~h}$. Both suspensions were rapidly taken up by the macrophages and few non-cell-associated organisms were detected in the stained monolayers (Fig. 2). The viability of the recombinant challenge declined steadily with time although usually at a slower rate than the vector control (Fig. 3). Little difference was seen in the percent infected macrophages in these monolayers or in the number of acid-fast bacilli (multiplicity of infection) per macrophage, even after $48 \mathrm{~h}$ incubation (Table 1). There was no evidence of intracellular growth by the recombinant in these macrophage monolayers, regardless of whether infection occurred in vitro (Fig. 3) or in vivo (Fig. 4).

\section{Protein antigens present in $\mathbf{r M}$. smegmatis J3R culture filtrates}

When culture filtrates from $\mathrm{r} M$. smegmatis J3R grown in PB'T medium were examined for protein bands by SDS-

PAGE, an intensely staining $65 \mathrm{kDa}$ band was observed

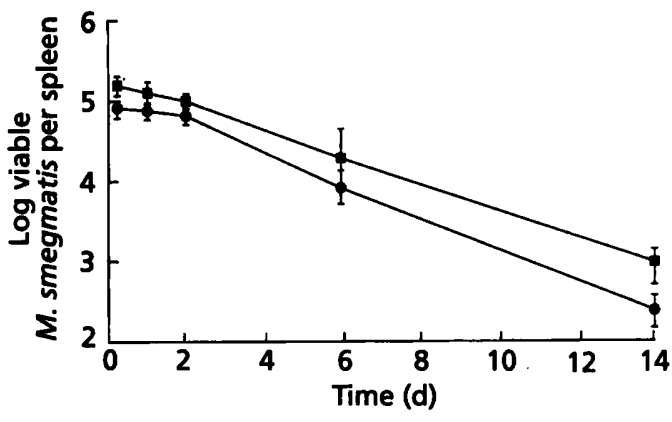

Fig. 1. Viability of the $\mathrm{rM}$. smegmatis pool $(\square)$ or vector control (O) in the spleens of C57BL/6 mice following intravenous inoculation with approximately $10^{6}$ c.f.u. of each strain in $0.2 \mathrm{ml}$ Tween/saline. The vertical bars represent the SEM for five determinations.

(Fig. 5, lane 3). Culture filtrates prepared from BCG were also characterized by a strong $65 \mathrm{kDa}$ protein band (lane 2) which was virtually absent from the vector control preparation (lane 4). A number of higher molecular mass $(80-120 \mathrm{kDa})$ bands were also present in the $\mathrm{r} M$. smegmatis and BCG culture filtrates, which were not present in the corresponding vector control preparation. This suggests that the recombinant was able to express transferred BCG gene(s) and so a study of the protective ability of this organism was undertaken in appropriately vaccinated mice.

\section{Protection of mice vaccinated with $\mathbf{r}$ M. smegmatis J3R}

C57BL/6 mice were infected intravenously with approximately $10^{8}$ c.f.u. $\mathrm{r} M$. smegmatis J3R suspended in $0 \cdot 2 \mathrm{ml}$ saline. Three weeks later they were challenged aerogenically with $10^{3}$ c.f.u. $M$. tuberculosis $\mathrm{H} 37 \mathrm{Rv}$, but the resulting growth curve indicated no increase in anti-

Table 1. Survival of $r M$. smegmatis J3R in mouse peritoneal macrophages

\begin{tabular}{|cccccc|}
\hline $\begin{array}{l}\text { Time } \\
\text { (h) }\end{array}$ & Strain* & \multicolumn{2}{c|}{ Macrophage infection } & $\begin{array}{c}\text { Viable count } \\
\text { (c.f.u. } \pm \text { SD) }\end{array}$ & $\begin{array}{c}\text { Survival } \\
\text { (\%) }\end{array}$ \\
\cline { 2 - 4 } & & $\begin{array}{l}\text { Percentage } \\
\text { infected }\end{array}$ & Multiplicity & & \\
\hline 0 & J3R & 65 & $1-5$ & $2 \cdot 7 \pm 0.38 \times 10^{4}$ & - \\
& VC & 58 & 5 & $1 \cdot 6 \pm 0 \cdot 87 \times 10^{4}$ & - \\
6 & J3R & ND & ND & $2 \cdot 8 \pm 0 \cdot 76 \times 10^{4}$ & 100 \\
& VC & ND & ND & $1 \cdot 2 \pm 0 \cdot 20 \times 10^{4}$ & 75 \\
24 & J3R & ND & ND & $1 \cdot 4 \pm 0 \cdot 13 \times 10^{4}$ & 52 \\
& VC & ND & ND & $5 \cdot 3 \pm 2 \cdot 10 \times 10^{3}$ & 33 \\
48 & J3R & 50 & $5-10$ & $7 \cdot 8 \pm 2 \cdot 40 \times 10^{3}$ & 29 \\
& VC & 64 & $2-5$ & $1 \cdot 5 \pm 0 \cdot 25 \times 10^{3}$ & 10 \\
\hline
\end{tabular}

ND, Not determined.

* J3R, rM. smegmatis J3R; VC, vector control. 


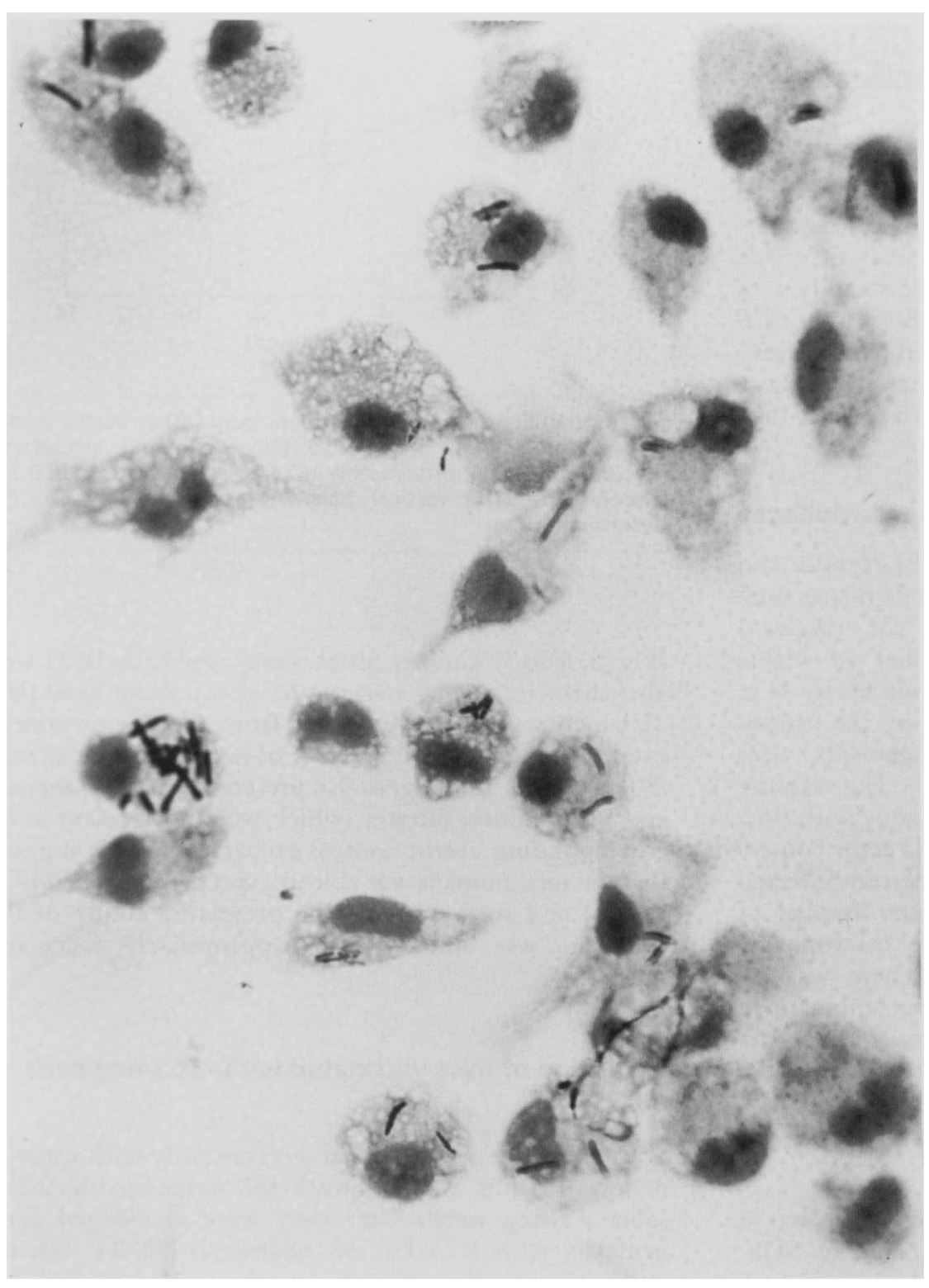

Fig. 2. Peritoneal mouse macrophages infected with $r M$. smegmatis J3R after $24 \mathrm{~h}$ incubation at $37^{\circ} \mathrm{C}$. The monolayer was stained by the Ziehl-Neelsen method $(\times 1000)$. tuberculous resistance, even when vaccination was given as 3 weekly doses of live organisms prior to challenge (V. Falcone, unpublished data).

In a second vaccination protocol, the C57BL/6 mice were injected subcutaneously with two doses of $20 \mu \mathrm{g}$ (approximately $10^{8}$ acid fast bacilli) heat-killed $r M$. smegmatis J3R suspended in $0.2 \mathrm{ml}$ Freund's incomplete adjuvant given after a 3 week interval (Collins \& Mackaness, 1970b). A group of control mice were vaccinated with a standard inoculum of live BCG Pasteur. The challenge inoculum in these mice was distinguished from the residual BCG by plating the lung homogenates on Middlebrook $7 \mathrm{H} 11$ agar containing $2 \mu \mathrm{g}$ thiophenecarboxylic acid hydrazide $\mathrm{ml}^{-1}$ (Collins \& Mackaness, 1970a). Other controls received Freund's incomplete adjuvant alone or $20 \mu \mathrm{g}$ killed vector control suspended in Freund's incomplete adjuvant. The vaccinated mice (together with age-matched unvaccinated controls) were challenged aerogenically with $10^{3}$ c.f.u. $M$. tuberculosis 3 weeks later and the growth of these organisms in the lungs and spleen was compared with the controls (Fig. 6). Mice receiving two doses of adjuvanted $\mathrm{r} M$. smegmatis showed a significant reduction in the number of viable $M$. tuberculosis present in the lungs $(P<0.01)$ and the spleen $(P=0.05)$ compared to the controls $28 \mathrm{~d}$ later. The reduction was only slightly less than that observed in the BCG vaccinated controls (Fig. 6).

\section{DISCUSSION}

Recent advances in gene cloning technology make it possible to transfer BCG genes to a variety of vectors, which will overproduce the specific protective antigen(s) to provide a long-lasting resistance to a subsequent tuberculous infection (Bloom, 1989). However, to be 


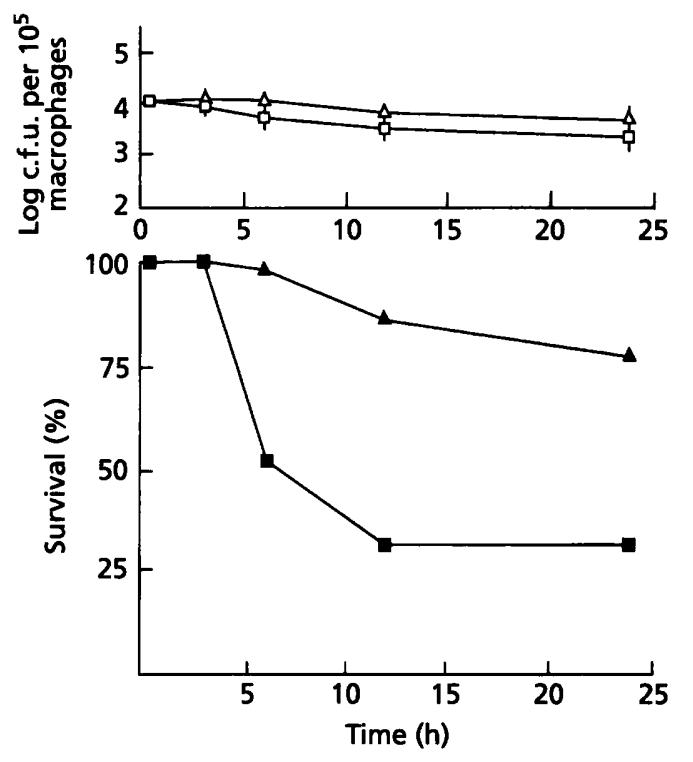

Fig. 3. Survival of $M$. smegmatis J3R $(\Delta, \Delta)$ and the vector control $(\square, \square)$ in peritoneal macrophages infected in vitro. The vertical bars represent the SEM for three determinations.

fully effective, the vector must be capable of establishing a persistent, self-limiting infection within the reticuloendothelial organs of the vaccinated host (Collins, 1991). Thus, the carrier must be able to survive in vivo for a long period of time without inducing detectable levels of immunopathology; the more persistent the infection, the better the protection (Curtiss et al., 1989). The $\mathrm{r} M$. smegmatis was eliminated from the mouse tissues at a slightly, though consistently slower rate than the vector

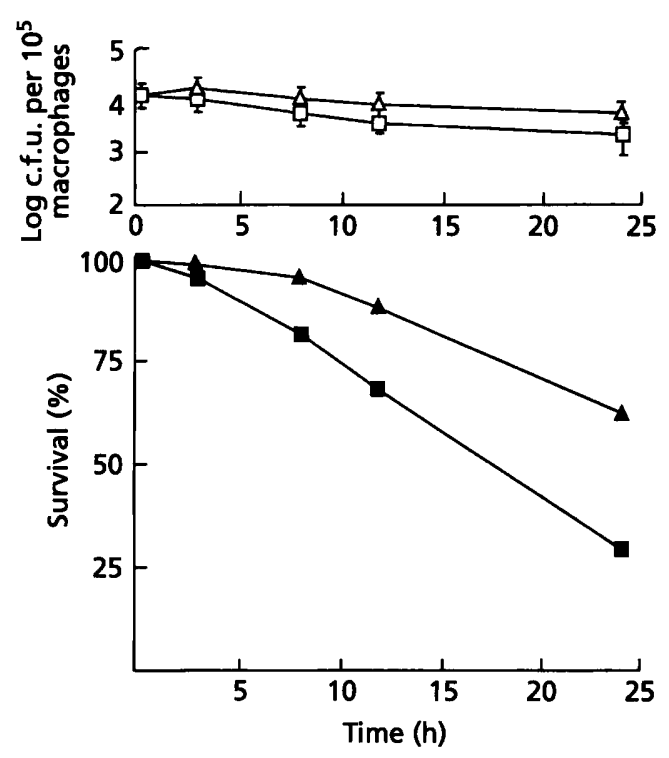

Fig. 4. Survival of $r M$. smegmatis J3R $(\triangle, \Delta)$ and the vector control $(\square, \square)$ in peritoneal macrophages infected in vivo. The vertical bars represent the SEM for three determinations.

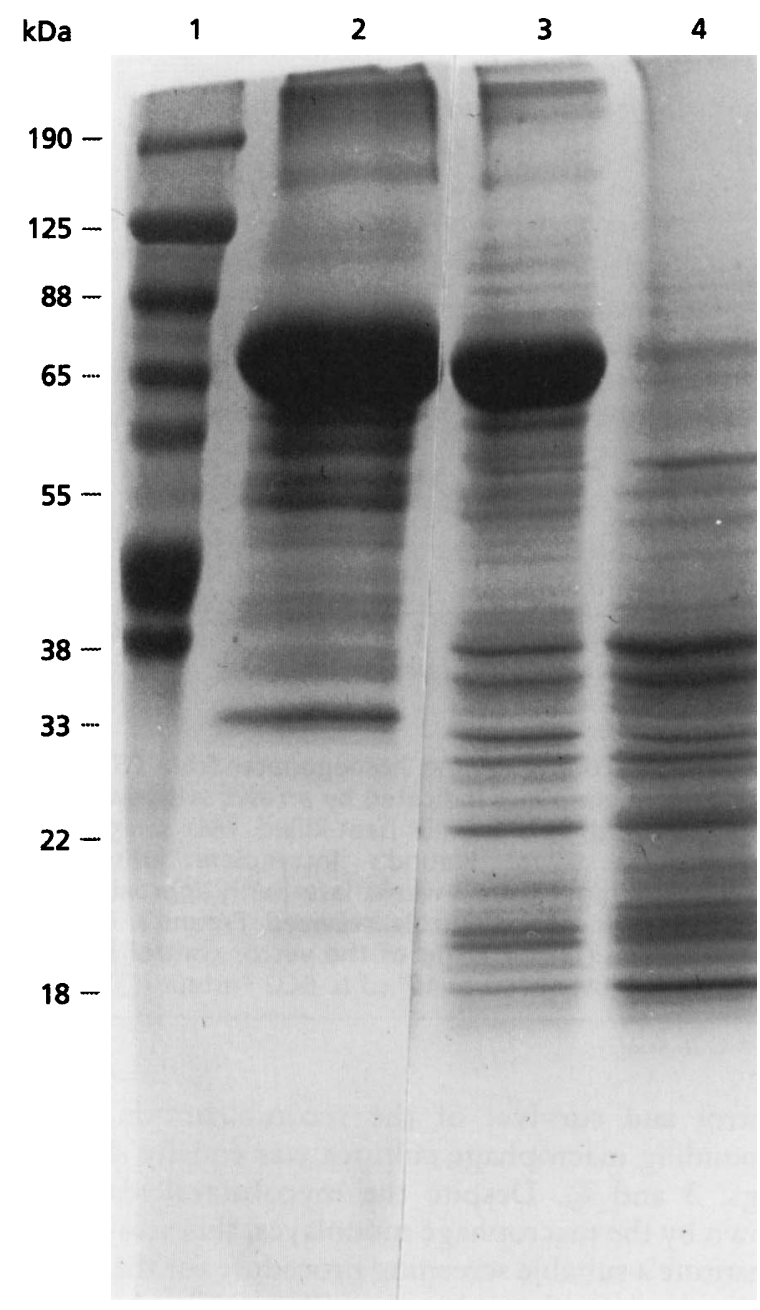

Fig. 5. SDS-PAGE gel showing culture filtrate proteins obtained from BCG (lane 2), rM. smegmatis J3R (lane 3) or the vector control (lane 4) when stained with Coomassie blue. Protein standards are shown in lane 1.

control (Fig. 1). Different commercially available BCG vaccines vary extensively in their persistence (and immunogenicity) when tested in mice or guinea pigs under standardized laboratory conditions (Lagrange et al., 1976; Wiegeshaus et al., 1971). Any new recombinant vaccine must induce a longer-lived, memory immune T-cell response than any of the existent strains of BCG (Collins, 1991). At present, we know very little about the antigens (or genes) responsible for inducing this type of persistent immune memory response (Orme, 1988).

The ability of mice to inactivate $M$. smegmatis has been ascribed to the presence of the $B c g^{r}$ gene and seems to be independent of an acquired T-cell-mediated immune response (Denis et al., 1990). These investigators reported substantial survival by $M$. smegmatis in peritoneal and splenic macrophages isolated from B10.A mice lacking the $B c g^{r}$ gene. In the present study, C57BL/6 $\left(B c g^{s}\right)$ mice rapidly inactivated both the $\mathrm{r} M$. smegmatis and its vector 


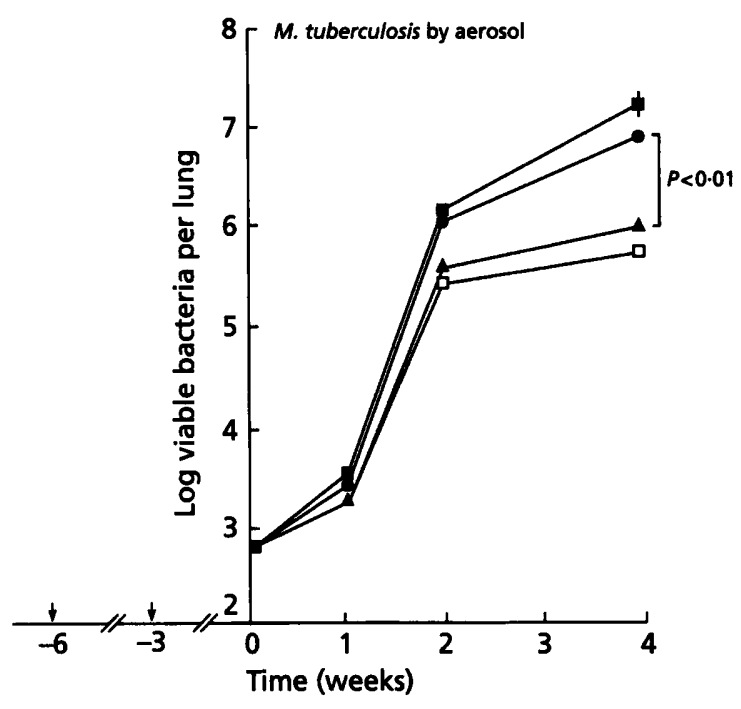

Fig. 6. Viable counts of lung homogenates from C57BL/6 mice vaccinated, at the times indicated by arrows, with two doses of $20 \mu \mathrm{g}\left(10^{8}\right.$ acid fast bacilli) heat-killed $\mathrm{rM}$. smegmatis J3R suspended in $0.2 \mathrm{ml}$ Freund's incomplete adjuvant and challenged aerogenically 3 weeks later with approximately $10^{3}$ $M$. tuberculosis (A). Controls received Freund's incomplete adjuvant alone ( $\mathrm{D})$, or $20 \mu \mathrm{g}$ of the vector control in Freund's incomplete adjuvant (O) or $10^{6}$ c.f.u. BCG Pasteur ( $\square$ ).

control and survival of the recombinant in the corresponding macrophage cultures was equally short-lived (Figs. 3 and 4). Despite the mycobactericidal activity shown by the macrophage monolayer, this assay may still constitute a suitable screening procedure for the detection of in vivo growth (ivg) genes (Pascopella et al., 1994) transferred from other mycobacterial species. The in vivo infection protocol has the additional technical advantage that phagocytosis occurred more efficiently at lower multiplicities of infection, resulting in fewer extracellular mycobacteria within the macrophage culture. The presence of gentamicin in the culture medium to prevent overgrowth by non-cell-associated organisms may explain the decreased survival of $M$. smegmatis noted in the present study compared to that reported in the earlier study (Denis et al., 1990).

In the present study, the BCG genomic library was expressed in $M$. smegmatis, which has long been known to be completely avirulent for both mice and people (Collins, 1983). Even when introduced into the tissues in massive numbers, the recombinant was inactivated before it could induce a detectable cell-mediated immune response to the transferred BCG antigens. The only way to achieve protection with this recombinant was to suspend the organisms in Freund's adjuvant administered as two doses over a 3 week interval. Under these experimental conditions, acquired resistance to the continued growth of the virulent $M$. tuberculosis challenge within the lungs of the J3R vaccinated mice was observed, a finding consistent with earlier protection studies carried out using this type of adjuvanted vaccine (Collins \& Mackaness, 1970b; Hubbard et al., 1992). Although the difference in viable numbers of $H 37 R v$ in the lungs of the $J 3 R$ versus vector control vaccinated mice was modest, it was statistically significant $(P<0.01)$ and comparable to that achieved using live BCG vaccine (Fig. 6). This difference correlated with increased survival by the J3R-vaccinated mice, none of which died during the 12 week challenge period, while all of the vector controls succumbed to the aerogenic challenge. The need for this type of adjuvant renders the present vaccine of little practical value for use in humans, but the mere fact that it worked at all makes this recombinant worth investigating further.

\section{ACKNOWLEDGEMENTS}

We thank Jean Martin, Louise Hartson and Carol Niederbuhl for technical assistance during this study. The work was supported by grants AI-26170, AI-26710 and AI-27146 from the National Institutes of Allergy and Infectious Disease, Bethesda and by a grant from CNR, PF-FATMA, Rome (VF).

\section{REFERENCES}

Bloom, B. R. (1989). New approaches to vaccine development. Rev Infect Dis 11, S460-466.

Collins, F. M. (1972). Salmonellosis in orally infected specific pathogen-free C57BL/6 mice. Infect Immun 5, 191-198.

Collins, F. M. (1983). Kinetics of the delayed-type hypersensitivity response in tuberculous guinea pigs and mice tested with several mycobacterial antigen preparations. $A m$ Rev Respir Dis 127, 599-604.

Collins, F. M. (1984). Protection against mycobacterial disease by means of live vaccines tested in experimental animals. In The Mycobacteria: a Casebook, vol. 2, pp. 787-839. Edited by G. P. Kubica \& L. G. Wayne. New York: Marcel Dekker.

Collins, F. M. (1985). Protection afforded by BCG vaccines against an aerogenic challenge by three mycobacteria of decreasing virulence. Tubercle 66, 267-276.

Collins, F. M. (1991). Anti-tuberculous immunity: new solutions to an old problem. Rev Infect Dis 13, 940-950.

Collins, F. M. \& Mackaness, G. B. (1970a). The relationship of delayed hypersensitivity to acquired antituberculous resistance. I. Tuberculin sensitivity and resistance to reinfection in BCGvaccinated mice. Cell Immunol 1, 253-265.

Collins, F. M. \& Mackaness, G. B. (1970b). The relationship of delayed hypersensitivity to acquired antituberculous resistance. II. Effect of adjuvant on the allergenicity and immunogenicity of heatkilled tubercle bacilli. Cell Immunol 1, 266-275.

Collins, F. M., Lamb, J. R. \& Young, D. B. (1988). Biological activity of protein antigens isolated from Mycobacterium tuberculosis culture filtrate. Infect Immun 56, 1260-1266.

Curtiss, R., Kelly, S. M., Gulig, P. A. \& Nahagama, K. (1989). Selective delivery of antigens by recombinant bacteria. Curr Top Microbiol 146, 35-49.

Denis, M., Forget, A., Pelletier, M., Servais, F. \& Skamene, E. (1990). Killing of Mycobacterium smegmatis by macrophages from genetically susceptible and resistant mice.J Leukocyte Biol 47, 25-30.

Fine, P. E. M. (1989). The BCG story: lessons from the past and implications for the future. Rev Infect Dis 11, S353-359.

Grosskinsky, C. M., Jacobs, W. R., Clark-Curtiss, J. \& Bloom, B. R. (1989). Genetic relationships among Mycobacterium leprae, $M$. tuberculosis and candidate leprosy vaccine strains determined by 
DNA hybridization: identification of an $M$. leprae-specific repetitive sequence. Infect Immun 57, 1535-1541.

Hubbard, R. D. \& Collins, F. M. (1991). Immunomodulation of mouse macrophage killing of Mycobacterium avium in vitro. Infect Immun 59, 570-574.

Hubbard, R. D., Flory, C. M. \& Collins, F. M. (1992). Immunization of mice with mycobacterial culture filtrate proteins. Clin Exp Immunol 87, 94-98.

Jacobs, W. R., Kalpana, G. V., Cirillo, J. D., Pascopella, L., Snapper, S. B., Udani, R. A., Jones, W., Barletta, R. G. \& Bloom, B. R. (1991). Genetic systems for mycobacteria. Methods Enzymol 204, 537-555.

Kim, T. H. \& Kubica, G. P. (1972). Long term preservation and storage of mycobacteria. Appl Microbiol 24, 311-317.

Lagrange, P. H., Miller, T. E. \& Mackaness, G. B. (1976). Parameters conditioning the potentiating effect of BCG on the immune response. In BCG in Cancer Immunotherapy, pp. 23-36. Edited by G. Lamoureux, R. Turcotte \& V. Portelance. New York: Grune and Stratton.

Orme, I. M. (1988). Characteristics and specificity of acquired immunologic memory to Mycobacterium tuberculosis infection. $J$ Immunol 140, 3589-3593.

Pascopella, L., Collins, F. M., Martin, J. M., Lee, M. H., Hatfull, G. F., Stover, C. K., Bloom, B. R. \& Jacobs, W. R. (1994). Use of in vivo complementation in Mycobacterium tuberculosis to identify a genomic fragment associated with virulence. Infect Immun 62, 1313-1319.
Snapper, S. B., Lugosi, L., Jekkel, A., Melton, R. E., Kieser, T., Bloom, B. R. \& Jacobs, W. R. (1988). Lysogeny and transformation of mycobacteria : stable expression of foreign genes. Proc Natl Acad Sci US A 85, 6987-6991.

Snapper, S. B., Melton, R. E., Mustafa, S., Kieser, T. \& Jacobs, W. R. (1990). Isolation and characterization of efficient plasmid transformation mutants of Mycobacterium smegmatis. Mol Microbiol 4, 1911-1919.

Stokes, R. W. \& Collins, F. M. (1988). Growth of Mycobacterium avium in activated macrophages harvested from inbred mice of different innate susceptibilities to mycobacterial infection. Infect Immun 56, 2250-2254.

Stokes, R. W., Orme, I. M. \& Collins, F. M. (1986). The role of phagocytes in the expression of resistance and susceptibility to Mycobacterium avium in mice. Infect Immun 54, 811-819.

Sudre, P., ten Dam, G. \& Kochi, A. (1992). Tuberculosis: a global overview of the situation today. Bull WHO 70, 149-159.

Wiegeshaus, E. H., Harding, G., McMurray, D., Grover, A. A. \& Smith, D. W. (1971). A co-operative evaluation of test systems used to assay tuberculosis vaccines. Bull WHO 45, 543-550.

World Health Organization. (1993). The global tuberculosis emergency. Press Release WHO/31.

Received 8 August 1994; revised 21 December 1994; accepted 5 January 1995. 